\title{
Pedro Henríquez Ureña y Alfonso Reyes en Argentina (1924-1930): una presencia de México en el Río de la Plata
}

\author{
Pedro Henríquez Ureña and Alfonso Reyes in \\ Argentina (1924-1930): \\ The Presence of Mexico in River Plate
}

\author{
Cecilia Guadalupe Neubauer \\ (D) 0000-0002-8669-9208 \\ Universidad Nacional Autónoma de México, México \\ gneubauer16@gmail.com
}

Resumen: Durante los años veinte, el mundo cultural rioplatense se encontraba en plena ebullición con la emergencia de la vanguardia artística y literaria, sumada a la emergencia progresiva del campo intelectual como espacio autónomo. El objetivo que perseguimos es analizar la presencia de los ex ateneístas Pedro Henríquez Ureña y Alfonso Reyes en el mundo de las revistas literarias del Río de la Plata entre los años 1924 y 1930. Esta presencia confirmó un diálogo novedoso con una realidad de igual talante: un espacio latinoamericano de reflexión y discusión. La originalidad del presente trabajo radica en el diálogo establecido entre los pensadores ya mencionados y los temas que impulsaron las publicaciones seleccionadas, como la Reforma Universitaria, el canon literario y la emergencia de la vanguardia argentina, a la vez de la generación de contactos con otras realidades continentales, como el estudiantado mexicano y el grupo literario conocido como Los Contemporáneos.

Palabras clave: revistas argentinas; vanguardia; Río de la Plata; Alfonso Reyes; Pedro Henríquez Ureña. 
Abstract: In the 20s, the River Plate cultural world was in full swing with the emergence of the artistic and literary vanguard, coupled with the progressive emergence of the intellectual field as an autonomous space. Our aim is to analyze the presence of former members of El Ateneo Pedro Henríquez Ureña and Alfonso Reyes in the world of the literary magazines of River Plate between 1924 and 1930. This presence confirmed a novel dialogue with a similar reality: a Latin American space for reflection and discussion. The originality of this article lies in the dialogue established between the aforementioned thinkers and the issues that drove the selected publications, such as University Reform, the literary canon and the emergence of the Argentine Vanguard, as well as the generation of contacts with other continental realities, such as the Mexican student body and the literary group known as Los Contemporáneos.

Key words: argentine magazines; vanguard; River Plate; Alfonso Reyes; Pedro Henríquez Ureña.

Fecha de recepción: 30 de noviembre de 2016 Fecha de aceptación: 27 de marzo de 2017

\section{INTRODUCCIÓN}

E n el marco de la estadía de Pedro Henríquez Ureña y de Alfonso Reyes en Argentina, entre los años 1927 y 1930, la ciudad de Buenos Aires ejercía una atracción centrípeta a nivel continental que llevó a muchos intelectuales y artistas a visitarla y ponerse así en contacto con los nuevos movimientos y manifestaciones en el terreno de las ideas y de la cultura. El contexto con el que se encontraron estuvo relacionado con la expansión de las redes generadas por la Reforma Universitaria de 1918, a la vez de la emergencia de la vanguardia literaria en el país, que provocó en el mundo de las letras argentinas severos cambios y reposicionamientos en el Buenos Aires de los años veinte. Fueron estas redes provenientes del reformismo-vanguardista que generaron un nuevo espacio de reflexión continental, a la vez que una apuesta a la creación de una identidad latinoamericana. El objetivo del presente trabajo entonces es desentrañar uno de los momentos de la conformación de esta red, caracterizado por la presencia de Pedro Henríquez Ureña y Alfonso Reyes en Argentina, quienes a través de las revistas literarias más significativas del momento colaboraron a la gestación de una nueva identidad continental.

\section{()(1) $(9$}


En este sentido, las publicaciones literarias constituyeron por aquellos años un espacio de debate acerca del "ser nacional", por lo que el encuentro con América resulta un cruce interesante. El mismo Henríquez Ureña (1929) en los Seis ensayos en busca de nuestra expresión, ya reflexionaba sobre la diversidad de formas en las que las naciones latinoamericanas abordaban su literatura como un espacio de creación de la cultura nacional: "Las naciones serias van dando forma y estabilidad a su cultura; mientras tanto, en las otras naciones, donde las instituciones de cultura, tanto elemental como superior, son víctimas de los vaivenes políticos y del desorden económico, la literatura ha comenzado a flaquear" (pp. 259-260).

En esta oportunidad nos proponemos analizar el vínculo de estos intelectuales con el momento cultural rioplatense para indagar ideas fundamentales que desarrollan Henríquez Ureña y Reyes en Argentina, la interacción con el medio y los resultados de este encuentro. En este sentido, se abordará la producción de ambos intelectuales en publicaciones como Nosotros, por tener una historicidad propia dentro del campo cultural de la época, Valoraciones, la publicación surgida del riñón del reformismo universitario, y Martín Fierro, símbolo de la naciente vanguardia literaria argentina.

\section{EL MUNDO DE LAS REVISTAS LITERARIAS EN EL RÍO DE LA PLATA}

La conformación y la relativa independencia que adquiriere el campo literario en la Argentina de las primeras décadas del siglo xx se encuentran estrictamente relacionadas con la emergencia de la vanguardia literaria en el país. En el marco de la modernización urbana, para Beatriz Sarlo (1997) el interés por independizarse de la tutela modernista de la revista Nosotros hizo surgir en el campo cultural de la época un espíritu renovador a la vez que una idea de "lo nuevo" ante un sentimiento de insatisfacción y reclamo. Así, para la década de 1920, las publicaciones se caracterizaron entre aquellas legitimadas por la corriente modernista de principios de siglo, como el caso de Nosotros, otras como Proa, atravesando un periodo de modernización, con nuevos planteos estéticos y políticos cuya tradición las enlazó con los postulados de la Reforma de 1918, y finalmente de ruptura como Martín Fierro, donde se impone una nueva estética, con una retórica agresiva con la consecuente liberación de la tutela modernista. La definición de una identidad nacional no se

\section{(1)(1) $(9$}


realizó sin tener en cuenta el problema de la lengua nacional, en un espacio de influencias múltiples a la vez que de reflexión de una tradición.

Siguiendo con lo anterior, la cultura letrada de este momento transcurrió por medio de un canal fundamental: las revistas literarias. Verdaderas polifonías (Romano, 2004), las revistas literarias son consideradas el elemento vinculante entre autores, lectores y el contexto, a la vez que permiten la relación con personalidades de la vida política del país, entre otros actores. Frente a esta problemática, persigo la intención de considerar las revistas intervenidas por Pedro Henríquez Ureña y Alfonso Reyes como un nudo que permite analizar las trayectorias nacionales en contextos continentales y la retroalimentación de los mismos.

En este sentido, algunos trabajos permiten analizar de modo próximo la relación entre el nacimiento de una literatura nacional y su soporte revisteril (Delgado, 2009), a la vez de convertirse en portavoces como en el caso de la Unión Latinoamericana y su boletín Renovación (Pita González, 2009), las redes entre José Carlos Mariátegui y sus vinculaciones con el campo cultural argentino gracias a publicaciones como La Vida Literaria de Samuel Glusberg (Tarcus, 2001), la importancia de las redes intelectuales del Ateneo de la Juventud para la consecución de empresas posteriores como la editorial Fondo de Cultura Económica (Myers, 2005) y un antecedente fuerte de este trabajo, que son las redes generadas desde la propia Reforma Universitaria (Bustelo, 2015). Así, tomando en cuenta contexto, actores, soportes y temáticas específicas, finalmente arribamos a la consideración de la revista cultural de la época como un texto colectivo, siguiendo a Benjamin, un documento de cultura (Beigel, 2003).

En este contexto, asomaron intelectuales interesados en desarrollar una actividad que los legitimara en el campo específicamente cultural; una actividad que requería cierta autonomía de las estructuras partidarias y que significaba al mismo tiempo un modo singular de intervención en los asuntos públicos. ${ }^{1}$ Insistimos en la circunstancia de que tanto el dominicano

\footnotetext{
${ }^{1}$ En este sentido, la investigadora Diana Quattrocchi-Woisson afirma que a lo largo del siglo xx pudieron haberse publicado en territorio argentino más de 2000 títulos de revistas culturales. Para más datos véase Quattrocchi-Woisson (1997). Por su parte, Francine Masiello (1986) realiza una caracterización de las publicaciones de la época, distinguiendo entre revistas cosmopolitas de contenido moderno modeladas sobre revistas europeas experimentales; las revistas anarcosindicalistas que defendieron los intereses del proletariado y las publicaciones más modernas dedicadas al estudio de lo moderno en cuanto experiencia generacional.
}

\section{()(1) $(9$}


como el mexicano pertenecientes a la generación del Ateneo de la Juventud, tomaron contacto con el universo rioplatense por primera vez a través de publicaciones literarias como Nosotros, emprendimiento de las letras argentinas cuya trascendencia superó las barreras nacionales al poner en contacto a diversos exponentes del modernismo literario desde inicios del siglo xx. Este ejemplo permite situarnos en el análisis de las revistas que haremos a continuación desde una perspectiva interdisciplinaria, que estudia la creación literaria, ideológica y cultural en relación directa con los contextos estéticos y sociopolíticos en los que emergieron y circularon, considerando tales publicaciones como parte fundamental del movimiento cultural y político de los países del continente (Crespo, 2010, p. 12).

A la hora de preguntarnos qué tipo de vínculos y relaciones pueden generarse entre Alfonso Reyes, Pedro Henríquez Ureña y su inserción en el terreno intelectual argentino, sería posible elaborar una geografía cultural (Sarlo, 1988) que permita elaborar representaciones literarias ligadas a espacios concretos en los cuales intervienen escritores y lectores de la obra. Las revistas -escribe Sarlo- tienen sus geografías culturales, que son dobles: el espacio intelectual concreto donde circulan y el espacio-bricolage imaginario donde se ubican idealmente.

Dicha geografía intentará abrazar también las formas de sociabilidad de la época en que ambos escritores se insertaron en la realidad literaria, por medio de prácticas de sociabilidad caracterizadas por conferencias, banquetes, reuniones, exposiciones artísticas y asociaciones culturales. Dichas geografías culturales permitirán elaborar un corpus de ideas que sirvieron a estos extranjeros para la reflexión sobre determinados tópicos centrales del momento o estructuras del sentimiento que dieron origen a obras ensayísticas y formas de pensar determinadas.

\section{PEDRO HENRÍQUEZ UREÑA Y ALFONSO REYES EN ARGENTINA}

El dominicano Pedro Henríquez Ureña llegó a Argentina a mediados de 1924, escapando de una serie de eventos desafortunados que provocaron su alejamiento de México debido a varios motivos. Desavenencias con José Vasconcelos, quien fuera un viejo compañero del Ateneo de la Juventud, y que por aquellos momentos se encontraba al mando de la recientemente conformada

\section{(1)(1) $(9$}


Secretaría de Educación Pública (SEP), sumadas a una intensa campaña xenófoba de parte de la prensa periódica debido a su labor en la Universidad, todo esto provocó su salida de México. Las redes conformadas desde el Congreso Internacional de Estudiantes de 1921, la convivencia durante aquellos días con la delegación argentina (recuérdese a sus integrantes: Héctor Ripa Alberdi, Arnaldo Orfila Reynal, Enrique Dreyzin, Pablo Vrillaud) insufló en un maduro Henríquez Ureña la posibilidad de poder proseguir su carrera literaria en un espacio en pleno auge: el Río de la Plata, el cual había tenido oportunidad de conocer gracias a una misión encabezada por el mismo Vasconcelos que se dirigió a Sudamérica, allá por 1922. Dicho viaje oficial tuvo como destino Brasil, Uruguay, Argentina, finalizando en Chile, donde la delegación mexicana pudo ponerse en contacto con una realidad que distaba de la que ofrecía el México posrevolucionario de Álvaro Obregón. La experimentación con las letras, el arte y el despegue intelectual gracias entre otras cosas al creciente grado de alfabetización vistos en Argentina, llevaron al dominicano a pensar en un posible traslado al sur del continente. Un periodo sombrío de malos negocios e incertidumbre, sumado a los arreglos realizados por las redes reformistas consolidadas, definieron el traslado de Henríquez Ureña a Argentina para ocupar un cargo como docente en el Colegio Nacional de La Plata. Entre varios intervalos, Henríquez Ureña permanecerá en Argentina hasta 1946, año de su trágica y prematura muerte.

Alfonso Reyes Ochoa, hijo de Bernardo Reyes quien pereciera en los sucesos de la Decena Trágica allá por 1913, es considerado el primer embajador de México en Buenos Aires, luego de que, a través de sucesivos proyectos, finalmente, para 1927, tanto México como Argentina decidieran elevar sus representaciones diplomáticas al rango de embajadas.

La elección de Reyes al frente de la representación mexicana en Buenos Aires obedecía a la necesidad de legitimar el proceso político mexicano desanudado con la revolución, por medio del cual la nación mexicana enviaba a los puntos más significativos del continente a intelectuales-diplomáticos, quienes por su trayectoria como letrados y miembros de la cultura proporcionaban al país la imagen de una nación civilizada, pero, sobre todo, pacificada.

Para mayo de 1927, a bordo del vapor Vauban, el literato mexicano era recibido en el puerto de Buenos Aires. Con ello se iniciaba un nuevo periodo en las relaciones México-Argentina. Con la presencia del intelectual en Buenos Aires, la representación mexicana se convirtió en un espacio de irradiación de la cultura mexicana en el Río de la Plata. La presencia del escritor en

\section{()(1) $(9$}


las revistas rioplatenses fue intensa y el diálogo entre las vanguardias argentina y mexicana fluido, como se verá a continuación.

Ambos en sus trayectorias individuales y como intelectuales públicos se convirtieron en portavoces del proceso posrevolucionario mexicano, a la vez que la recepción del mismo estuvo íntimamente relacionada con dos aspectos. Nos aventuramos a considerar dos embajadas mexicanas en Buenos Aires, una cultural, heredera de los postulados del Ateneo de la Juventud mexicano, que tuviera como uno de sus maestros al propio Henríquez Ureña, y debido a sus funciones, una político-diplomática representada por Alfonso Reyes. Ambos gentleman escritores, fueron partícipes de los cambios arriba mencionados en el mundo literario de la época. Las colaboraciones ofrecidas rebelan las filias y fobias de ambos, ya que mientras Henríquez Ureña orienta sus actividades hacia el terreno conocido representado en Nosotros, y el estudiantil debido a su experiencia acumulativa iniciada en México, Reyes se inclina por el aporte a las publicaciones de la vanguardia local. Como veremos, entre sus actividades, la puesta en contacto con el experimento mexicano de Los Contemporáneos, mismo del que se desencantará tiempo después, estuvo entre sus aportes más significativos.

En el rastreo de las colaboraciones de Henríquez Ureña y Reyes en revistas rioplatenses, se pondrá especial atención en los modos de intervención sobre el panorama local, como los canales de promoción de la nueva generación literaria mexicana en Buenos Aires (nos referimos a la generación de jóvenes como Daniel Cosío Villegas, Eduardo Villaseñor, Xavier Villaurrutia, Salvador Novo, Manuel Rodríguez Lozano, entre otros), así como múltiples impresiones de la situación continental sobre la que se sitúan las dos realidades nacionales, la argentina y la mexicana, espacios nacionales de estructuración de la red intelectual.

Como en aquellos años mexicanos, es el dominicano quien ejerce su labor de maestro sobre el mexicano, guiándolo dentro de los múltiples caminos que conforman las publicaciones porteñas de la época. Acerca de la posibilidad de publicar en Argentina, el dominicano aconseja al mexicano en una carta (Henríquez y Reyes, 1986): "[A] La Nación, artículos serios, un poco divulgación, un poco actualidad [...] A Nosotros lo más tuyo, aquello en que digas lo que se te dé la gana [...] habría que añadir Martín Fierro de Girondo en igual consideración. A Valoraciones, que sale tres o cuatro veces por año, lo que quieras" (p. 98).

\section{()(1)(8)}


En esta breve reseña, Pedro Henríquez Ureña identifica algunas de las publicaciones más sobresalientes de la época, a la vez que las posiciona dentro del terreno literario local. Este espacio se encuentra, por una parte, hegemonizado por el matutino La Nación, representante de las elites intelectuales, y la revista Nosotros, la voz de autoridad en el campo literario de la época, y, por otra parte, Proa, Valoraciones y Martín Fierro: las tres pequeñas publicaciones de una nueva generación en disputa por la apropiación del campo literario, de las cuales surge la vanguardia literaria. Fue en su seno donde comenzaron a surgir nombres de la talla de Jorge Luis Borges, Leopoldo Marechal, entre otros. Junto con ellos en 1929 Alfonso Reyes concibe el ya mencionado proyecto Cuadernos del Plata, una serie de plaquettes destinados a dar a conocer lo más relevante de la literatura contemporánea en Argentina. Evar Méndez se haría cargo del contenido editorial, mientras que Reyes (2010) se haría cargo de la parte literaria:

Sueño los nombres siguientes: Pedro Henríquez Ureña, Victoria Ocampo, Jorge Luis Borges, Diego Rivera (+), Ricardo Guiraldes (inéditos), Oliverio Girondo (+), Francisco Luis Bernárdez, Sergio Piñero hijo (inédito) ¿González Lanuza? Xul Solar (+), Ricardo Molinari, ¿Eduardo J. Bullrich?, Genaro Estrada, Antonio Castro Leal, Julio Torri, Antología Yanqui traducida por los chicos mexicanos. Los que llevan (+) son, además, dibujantes. Y hay también los dibujantes siguientes: Norah Borges, Pettorutti, Silvina Ocampo, Orozco, C. González, etc. (pp. 77-79).

Al ver los nombres mencionados, el proyecto toma ribetes continentales, ya que se involucra a algunos de los jóvenes mexicanos Contemporáneos, en un intento de aunar a las vanguardias de ambos extremos del continente. Los Cuadernos del Plata se convierten así en una posibilidad de diálogo entre los proyectos literarios de la juventud argentino-mexicana con los intelectuales consagrados. ${ }^{2}$

${ }^{2}$ La serie Cuadernos del Plata quedó conformada de la siguiente manera: Seis relatos, de Ricardo Guiraldes, Cuaderno San Martín, de Jorge Luis Borges, Papeles de reciénvenido, de Macedonio Fernández, El pez y la manzana, de Ricardo Molinari, Línea, de Gilberto Owen. Concretamente, la ansiada cofraternidad argentino-mexicana no fue fructífera. Envidias, recelos, negativa de los argentinos a colaborar con la recientemente aparecida Contemporáneos (de lo cual Alfonso Reyes escribe a Genaro Estrada en sus cartas), llevan al embajador a reflexionar sobre el momento literario argentino como cerrado y negativo. Culto a Mallarmé y Testimonio de Juan Peña también fueron plaquettes impresas en Argentina en la localidad de San Antonio de Areco, por el impresor de Ricardo Güiraldes (Reyes y Ocampo, 1983).

\section{()(1) $(9$}


En ese sentido, no debe soslayarse que los textos publicados de Henríquez Ureña y de Reyes en revistas argentinas que hemos seleccionado son ensayos, lo cual nos lleva a pensar con Liliana Weinberg (2013) de qué manera dicho género en América Latina construyó una historicidad propia que permite diálogos con la realidad del momento y permite entretejer redes de sociabilidad intelectual: "El ensayo reproduce formas de sociabilidad intelectual, y que a su vez, a través de su capacidad para la intermediación entre discursos y prácticas, esferas e instituciones, contribuye a consolidar -e incluso contribuye a postular- un espacio de encuentro para la confluencia de líneas de pensamiento y redes de intercambio de ideas (p. 1)."

En consecuencia, la estadía de Pedro Henríquez Ureña y Alfonso Reyes en el contexto rioplatense y su producción en las revistas literarias que presentaremos a continuación permite analizarlos en torno a la definición de una voz latinoamericana en la Argentina de aquellos años y a la construcción de una identidad regional, heredera de procesos como el reformismo universitario y la revolución mexicana. Sin embargo, la polifonía del discurso implícito en las revistas seleccionadas tampoco es inocente, sino que la operación de selección de los artículos obedece a una toma de postura estrechamente vinculada a las ideas fuerza que sostienen a las publicaciones. Veremos cómo, según la publicación, Reyes y Henríquez Ureña se convierten en portavoces de ideas vinculadas enteramente a una realidad continental, y en otras ocasiones, los intereses discurrirán en temas más relacionados con el acontecer nacional argentino.

\section{LA HEGEMONÍA DE NOSOTROS EN LAS LETRAS ARGENTINAS DE PRINCIPIOS DE SIGLO}

Fundada el 1 de agosto de 1907, con una permanencia de varias décadas hasta su fin en 1943, la revista Nosotros es considerada el documento más importante de la vida intelectual argentina de las primeras cuatro décadas del siglo xx (Lafleur, Provenzano y Alonso, 1968). Como ya se ha afirmado, la revista era

\footnotetext{
${ }^{3}$ Otro tanto ha sucedido con el paso de la vieja historia de las ideas a la nueva historia intelectual que, "gracias a su atención al contexto", considera el surgimiento, desarrollo y declive de ciertos corpus de ideas atendiendo a las circunstancias históricas en el momento de su aparición (Weinberg, 2013).
}

\section{()(1) $(9$}


conocida desde 1908 por Henríquez Ureña y Reyes, los cuales intercambiaban impresiones acerca de la calidad literaria de esta publicación. Sus directores y principales impulsores son Alfredo A. Bianchi y Rodolfo Giusti. ${ }^{4} \mathrm{La}$ vida de la revista estuvo jaloneada de hechos resonantes, banquetes, almuerzos, recepción de visitantes ilustres (como veremos con la llegada de Alfonso Reyes), y controversias con gente nueva en el campo de las letras, a la que terminaba siempre por apadrinar. Nosotros se constituye en órgano de consagración y difusión cultural y, en consecuencia, el grupo que funciona en torno a ella. Giusti y Bianchi, los directores, son algo así como los organizadores intelectuales del periodo, hasta el surgimiento de la disidencia encarnada en Martin Fierro, que disputa a Nosotros la supremacía del campo (Sarlo, 1997).

Como ya se ha mencionado, mucho antes de su arribo a la Argentina, Pedro Henríquez Ureña y Alfonso Reyes fueron colaboradores activos de la publicación. Pero para los años de su residencia entre Buenos Aires y La Plata, Nosotros comenzó a languidecer. Su declive tiene dos explicaciones: el avance del cosmopolitismo o una vinculación estrecha con el panorama internacional, ello explica el ascenso de Sur, cuando Nosotros se encontraba en franco declive, y la muerte en el ' 43 de Alfredo Bianchi, uno de sus fundadores. Podría intuirse en el fin de Nosotros el recambio generacional entre un grupo caracterizado por un momento preciso, de estructuración de las premisas fundamentales de la nacionalidad, a otro de corte universalista, destinado a tender puentes hacia el afuera del país, sobre todo a Europa.

\section{LOS REFORMISTAS UNIVERSITARIOS Y LA REVISTA VALORACIONES}

Bajo este título, el grupo de estudiantes Renovación editó su primer número en septiembre de 1923 en La Plata. Tuvo un claro objetivo, el de divulgar las empresas culturales del momento, relacionadas con el ámbito estudiantil. Esta agrupación, dependiente de la federación de estudiantes de la Universi-

${ }^{4}$ Editada en Buenos Aires por la Compañía Sudamericana de Billetes de Banco, ante la dificultad declarada de mantener una revista exclusivamente literaria por aquellos tiempos y luego de fracasar dos veces. Para 1910 la revista tuvo que interrumpir un año su publicación. En julio de 1912, ante crecientes dificultades económicas, se organizó la sociedad cooperativa Nosotros, presidida por Rafael Obligado, que cambió el formato de la publicación, aumentó su número de páginas y vio acrecentar el número de colaboradores.

\section{()(1) $(9$}


dad de La Plata, fue protagonista de los sucesos de la aplicación de los postulados reformistas en el seno de dicha institución.

Desde sus primeras "Intenciones" (así se llama su primer artículo), la acción de la revista abarcó todas las manifestaciones de la vida nacional y extranjera, deteniéndose especialmente en aquellos hechos o ideas que, de algún modo, contribuían a la definición histórica del momento (Intenciones, 1923, p. 4).

Asimismo, otro de sus propósitos fue impulsar los ideales de la reforma universitaria, reflejados en la participación del estudiantado en el terreno de las letras y la cultura: "Haremos efectiva la Reforma en la manera honesta como nosotros la entendemos: superación mental del estudiante y crítica del profesorado. En las páginas de Valoraciones trataremos de hacer en ese sentido, una labor constructiva, orientando a la juventud hacia rutas fundamentales de alta cultura" (Intenciones, 1923, p. 4).

Cabe destacar que algunos de los miembros del grupo Renovación, como Héctor Ripa Alberdi, Enrique Dreyzin y Pablo Vrillaud, tomaron contacto por vez primera con el magisterio de Henríquez Ureña, la amistad de Daniel Cosío Villegas, a través del Congreso Internacional de Estudiantes celebrado en México en 1921. Así, crecía un espacio de referencias cruzadas entre México y Argentina. La utopía de una internacional de estudiantes creó un universo de relaciones que el gobierno mexicano supo aprovechar; así, en Argentina, jóvenes universitarios fueron sumando su apoyo, otorgando densidad continental al respaldo que el gobierno de Obregón recibía por parte de la propia intelectualidad mexicana (Yankelevich, 1997, p. 269). Esta fructífera amistad entre mexicanos (considerando dentro de este primer grupo a Henríquez Ureña) y los argentinos visitantes, posibilitó el surgimiento de una red de colaboraciones mutuas que tuvo como consecuencia el acercamiento de las realidades argentina y mexicana en las páginas de la revista. Por medio de esta publicación, los lectores pudieron conocer el panorama de la nueva pintura mexicana, de la mano de Daniel Cosío Villegas, obras de pintores mexicanos como Manuel Rodríguez Lozano y Diego Rivera o Julio Castellanos; sobre La política religiosa en Méjico [sic] en pleno conflicto cristero y los Estudios indostánicos de José Vasconcelos.

Finalmente, estas redes juveniles de solidaridad se tradujeron en la toma de contacto de Pedro Henríquez Ureña con Rafael Alberto Arrieta, director del Colegio Nacional de La Plata que, como ya hemos visto, posibilitarán la ayuda, junto con Genaro Estrada, para el traslado de Henríquez Ureña al Río de la Plata. El magisterio del dominicano permeó las conciencias de

\section{()(1) $(9$}


estudiantes argentinos hasta su muerte en 1946. Así, las colaboraciones del dominicano en Valoraciones fueron regulares, como también su definida postura a favor del estudiantado y su derecho a representación en los ámbitos de decisión en universidades. Henríquez Ureña fue adoptado por la comunidad del grupo Renovación, junto a Alejandro Korn y José Ingenieros, como uno de los maestros de la juventud rioplatense.

En este sentido, al indagar los vínculos entre Pedro Henríquez Ureña y la problemática universitaria, aquellos se remontan hasta los años 1913-1914, donde presentó en la Universidad Nacional de México su tesis "La Universidad", para obtener el grado de abogado. Henríquez Ureña realizó en ella una defensa de los claustros universitarios, tomando como referencia la labor de Justo Sierra y los ateneístas al crear la Universidad Popular Mexicana en 1912 (Melgar, 2010). ${ }^{5}$

Como institución dedicada a cumplir fines de alta cultura y de cultura técnica, la universidad debe, según el dominicano, estar sostenida económicamente por el Estado, cobijando a los grandes maestros guardianes de la alta cultura. Sin ellos, el país no tendría buenos hombres de profesión ni de enseñanza; "vegetarán sus empresas, sus construcciones, sus leyes, sus escuelas. Las escuelas elementales son imperiosa necesidad social; pero no pueden prosperar si no son la base de una pirámide cuya cima es la universidad" (Henríquez Ureña, 1969, p. 74). A modo de conclusión de su trabajo de tesis, Henríquez Ureña elaboró una reflexión que, sin duda, tiene muchos puntos en común con los postulados de la reforma universitaria. La universidad, considerada por este, como una "república aristocrática":

En cuyas asambleas se oyera la voz de los mejores, pero en representación de todos; es donde junto a la palabra del rector sonará la del alumno y junto a la del representante del Poder Ejecutivo la del delegado libremente electo por los profesores; núcleo coordinador, donde la discusión depurara las ideas de

${ }^{5}$ La Universidad Popular Mexicana fue creada por el núcleo del Ateneo de la Juventud en 1912 y logra sobrevivir hasta 1920. Su objetivo era el de ampliar el mundo del conocimiento trasladándolo fuera de los espacios universitarios. Además de Henríquez Ureña, sus principales ideólogos fueron el español Pedro González Blanco y Alfonso Pruneda. La cultura debía llegar a las clases más numerosas, tendrían que acercarse al pueblo dentro de la mística que entrañaba el cambio político y social. Trabajadores y obreros serían los invitados a participar. No sería un programa gubernamental, sino que dependería de apoyos privados. Su lema: "La ciencia protege a la patria" (Melgar, 2010).

\section{()(1) $(9$}


cada grupo y las tendencias de cada escuela; donde la tradición significara corriente, nunca rota pero nunca estancada, de doctrina y de esfuerzo a la cual se sumaran cuanto de estimulante aportasen el antes desconocido profesor libre y el universalmente famoso profesor extranjero (p. 83).

Con el experimento de la Universidad Popular Mexicana de 1912 en apoyo a la noción de extensión universitaria, concluimos que no sólo el pensamiento sino también la acción del dominicano en tierras mexicanas se anticipa en más de un lustro a la Reforma Universitaria argentina de 1918 y otorga credenciales para que los estudiantes consideren a Pedro Henríquez Ureña como uno de los maestros del proceso reformista.

La Universidad como sujeto fundamental de análisis en el discurso del dominicano y el acompañamiento a los actores protagonistas de la Reforma Universitaria rioplatense sí fueron elementos importantes más no suficientes para la consagración de Henríquez Ureña como referente del pensamiento continental en Argentina. El "maestro de América" sólo lo fue de manera nominal, ya que Pedro Henríquez Ureña nunca obtuvo ninguna cátedra en las universidades de La Plata ni de Buenos Aires. Como ha señalado Arcadio Díaz Quiñones (2006, pp. 214-215), la cuestión racial y su ascendencia caribeña tuvieron un peso diferenciador en la Argentina de aquellos años.

\section{Los reformistas universitarios y el fenómeno mexicano}

La participación de Henríquez Ureña en Nosotros y Valoraciones estuvo vinculada a los homenajes realizados a los estudiantes Héctor Ripa Alberdi y a Enrique Dreyzin, asistentes al congreso de estudiantes de 1921, la instancia que permite aunar el espíritu reformista de los estudiantes argentinos con la realidad mexicana posrevolucionaria.

Publicado bajo el título "Héctor Ripa Alberdi" por Nosotros, el texto también se conoce con el nombre "El amigo argentino". Editado en la obra Seis ensayos en busca de nuestra expresión (1928) de Henríquez Ureña, este artículo sirvió de prólogo a la edición de las obras completas de Ripa Alberdi en dos volúmenes en $1925 .^{6}$

${ }^{6}$ Dato rastreado en Notas a seis ensayos en busca de nuestra expresión (Henríquez, 2001, p. 327). 
En dicho artículo, el dominicano realiza una semblanza de la vida del representante estudiantil a modo de homenaje por su repentina muerte. Recordemos que el encuentro entre Henríquez Ureña y Ripa Alberdi tuvo lugar en el marco del congreso realizado en México, siendo Pedro Henríquez Ureña representante por la delegación de su país de origen, República Dominicana, y el segundo, parte de la delegación de estudiantes argentinos, portadores de las experiencias del reformismo universitario. Según el dominicano, "despertaba interés la delegación argentina, sabíamos que llevaba la representación del movimiento que había renovado las universidades de su país" (Henríquez, 2001). El encuentro con Ripa Alberdi constituyó para Henríquez Ureña una "revelación íntima de la Argentina", ya que veía asomar al Río de la Plata y a sus escritores a través de este grupo de embajadores de la cultura y el porvenir de nuestra América:

Cosa mejor: la juventud de aquel país, grande y próspero, país de empresa y de empuje, se orientaba con generosidad y desinterés hacia el estudio de los problemas sociales, $y$ le preocupaban, no el éxito ni la riqueza, aunque se pretendiera asignarles carácter nacional, sino la justicia y el bien de todos. Cabía pensar que nuestra América es capaz de conservar y perfeccionar el culto a las cosas del espíritu, sin que la ofusquen sus propias conquistas en el orden de las cosas materiales. Rodó no había predicado en el desierto (Henríquez Ureña, 1925, p. 498).

Henríquez Ureña retoma el discurso que ofreció Ripa Alberdi al auditorio de la Escuela Nacional Preparatoria en el que, entre otras cosas, afirma que:

[Ripa] comenzó pensando en la renovación de las universidades argentinas; de ahí pasó al ansia de una cultura nacional, modeladora de una patria superior. Estos anhelos se enlazaron con otros: por una parte, la cultura nacional no podía convertirse en realidad clara si no se pensaba en la suerte del pueblo sumergido, del hombre explotado por el hombre, para quien la democracia ha sido redención incompleta; por otra parte, el espíritu argentino no vive aislado del Nuevo Mundo: la fraternidad, la unión moral de nuestra América, la fe en la magna patria, son imperativos necesarios de cada desenvolvimiento nacional (Henríquez Ureña, 1925, pp. 498 y 502).

\section{()(1) $(9$}


Es interesante tener en cuenta la ligazón de las temáticas entre el joven estudiante y el maestro dominicano. El espíritu de nuestra América es una investigación acerca de nuestra expresión, en el pasado y en el futuro (Henríquez, 2001, p. 326). Otro artículo relacionado con la inesperada muerte de Ripa Alberdi fue "Poeta y luchador", también escrito por Pedro Henríquez Ureña y publicado en Valoraciones, en que el dominicano ve plasmados los ánimos de la Reforma Universitaria:

Así como este hombre sereno en su país de hombres inquietos, pudo ser uno de los animadores de aquel formidable movimiento que en 1918 agitó las banderas de las escuelas argentinas y las obligó a renovarse. La juventud demandaba la autonomía eficaz de las Universidades, la participación del estudiante en los consejos que determinan orientaciones, la renovación de las ideas y de los hombres (Henríquez Ureña, 1924, pp. 95-96).

Con Ripa Alberdi al frente de la delegación de estos jóvenes, la juventud americana pudo entrar en conocimiento del fenómeno reformista. A la vez, los estudiantes argentinos lograron interiorizarse del hecho revolucionario y su saldo positivo, que pronto comunican a la comunidad universitaria platense, lo cual se pone de manifiesto durante la visita de José Vasconcelos en 1922 a Argentina. Henríquez Ureña recuerda:

México le interesó profundamente: le sedujo su honda agitación cobijada por la solemne paz de su naturaleza. Y a su patria volvió con sus compañeros para comunicar a todos la fe en el México nuevo. Cuando en 1922 visitamos la ciudad universitaria de La Plata [sic], encontramos el "ambiente mexicano" creado en ellos: no sólo los versos de los poetas mexicanos, sino las estampas de edificios coloniales, las canciones del pueblo, repetidas por la juventud, el entusiasmo por las ideas mexicanas... Desde hace dos años, México es para aquella juventud símbolo de la pujanza con que la América Latina concibe los ideales de una civilización nueva, original, más amplia y generosa que todas (Henríquez Ureña, 1924, pp. 95-96).

Un tema que deja entrever el dominicano, y que se convierte rápidamente en una de sus preocupaciones más importantes, es aquel que considera a la América española como una nación en su totalidad, en busca de su expresión genuina, sobrepasando los límites de las nacionalidades. Estas reflexiones se-

\section{()(1) $(9$}


gún Carolina Sancholuz (2013, p. 91) madurarán en los Seis ensayos en busca de nuestra expresión, editado por Babel, la empresa de Samuel Glusberg, en 1928.

Asimismo, la publicación parece ser tomada como medio de promoción de las nuevas obras. Esto sucede en el caso de Alfonso Reyes, quien en varias oportunidades utiliza Valoraciones para dar a conocer, por ejemplo, algunos fragmentos de su obra Calendario, la cual se encontraba en prensa en Madrid (Reyes, 1924, pp. 120-122). En el mismo sentido, Pausa (1926), reseña de Jorge Luis Borges del libro de poemas escrito por Reyes en París, encuentra su espacio en la revista para divulgar la última obra de Reyes. Esto último nos habla del espacio en Valoraciones para la construcción de filias literarias con Alfonso Reyes.

Para 1928 vuelven a ponerse en marcha las solidaridades entre aquellos participantes del Congreso de Estudiantes celebrado en México. En dicha oportunidad, se trató de homenajear a Enrique Dreyzin, otro de los jóvenes de la delegación argentina conocidos por Henríquez Ureña, allá por 1921. Al tomar la palabra, Henríquez Ureña lo hace en nombre de México, acompañado de su embajador, Alfonso Reyes, para decir que:

Sé que asisten aquí con Alfonso Reyes y conmigo, en dolor, en espíritu y en carne aquellos amigos de Dreyzin que se llaman José Vasconcelos, Diego Rivera, Manuel Rodríguez Lozano, Roberto Montenegro, Julio Torri, Carlos Pellicer, Alfonso Caso, Vicente Lombardo Toledano, Manuel Gómez Morin, Daniel Cosío Villegas, Eduardo Villaseñor (Henríquez Ureña, 1928, p. 258).

La remembranza de aquel Congreso reaviva las amistades y solidaridades allí selladas, pero también aviva el recuerdo de Héctor Ripa Alberdi, estudiante conocido por el dominicano:

Vimos [en esos días] el feliz acercamiento de dos almas que son los focos de la elipse de la América nuestra, México y la Argentina. Cada uno daba su nota en aquel concierto de voluntades claras. Dos se extinguieron ya: la nota de Héctor Ripa Alberdi, que fue bondad, firme y discreta, y la nota de Pablo Vrilland [sic], que fue cordialidad enérgica y vivaz. La de Enrique Dreyzin fue franqueza alegre (Henríquez Ureña, 1928).

Las colaboraciones de Pedro Henríquez Ureña en Valoraciones revelan una íntima filiación con el proceso estudiantil desatado en 1918. Homenajes

\section{()(1) $(9$}


fraternos a referentes estudiantiles y la revalorización creciente de lo americano en términos literarios, son los elementos clave de la inserción del dominicano en el panorama gráfico del movimiento estudiantil argentino. Las ideas del maestro Henríquez Ureña, sumadas a un contexto de democratización paulatina de los gobiernos de las universidades argentinas, provocaron la vinculación de los temas argentinos con el resto de América.

\section{LA EMERGENCIA DE LA VANGUARDIA: LA REVISTA MARTÍN FIERRO}

A finales de 1923 y principios de 1924, convocados por Evar Méndez ${ }^{7}$ y Samuel Glusberg, ${ }^{8}$ un grupo de jóvenes se reunió en la confitería La Cosechera de la Avenida de Mayo, y la Richmond, de la calle Florida en Buenos Aires, para fundar una revista. Resultó llamativo que decidieran utilizar por tercera vez el nombre de Martín Fierro. Si bien el proyecto incluía temas políticos y artísticos del momento (Salas, 1994, p. 8).

Dicha versión del surgimiento de Martín Fierro trajo consigo el surgimiento de la vanguardia artística en el país. El nombre que la revista adoptó en 1924 y conservó hasta su desaparición puede explicarse sólo por la historia anterior que vincula a este segundo Martín Fierro con el primero de 1919 y a estos con el suplemento de La Protesta editado en la primera década del siglo (Sarlo, 1997, p. 23). Estas tres publicaciones con contenidos diversos entre sí que llevaron el mismo nombre deben ser consideradas como parte fundante de una disputa por la pertenencia e identificación nacional, en la que estuvo involucrado todo el arco intelectual argentino.

En este contexto de cambios múltiples y de miradas hacia el extranjero, nace Martín Fierro como una revista joven, transgresora, moderna, icono-

${ }^{7}$ Guillermo Evaristo González Méndez (1885-1955). Fundador de la revista Martín Fierro. Miembro de una ilustre familia conservadora, su interés por el arte moderno abrió puertas a artistas como Emilio Pettoruti, Xul Solar y Norah Borges. La labor de Méndez al frente de proyectos editoriales fue pionera en el país. Para más datos, véase: http://letras-uruguay. espaciolatino.com/aaa/garcia_carlos/evar_mendez.htm [Consulta: 20 de octubre de 2013.]

${ }^{8}$ De origen judío, solía utilizar el seudónimo de Enrique Espinoza para sus trabajos. Fue uno de los promotores editoriales más importantes de la época. Radicado en Chile, funda su editorial Babel, gracias a la cual son publicados trabajos de Guiraldes, Borges, Henríquez Ureña, Mariátegui, entre otros escritores latinoamericanos. El saldo de dicha empresa editorial fue la creación de una plataforma continental de producción intelectual.

\section{(1) (1)}


clasta, irrespetuosa y dotada de un enorme sentido del humor. El momento histórico, además, coincidió con la aparición generacional de los que habrían de ser algunos de los mayores escritores de la literatura nacional, como Jorge Luis Borges, Leopoldo Marechal, entre otros, quienes durante poco más de tres años encontraron cobijo en sus páginas (Salas, 1994, p. IX).

Para Beatriz Sarlo, la insistencia del nombre de la revista alude a la cuestión de la nacionalidad cultural. En ese sentido, el manifiesto de la publicación afirma que:

Frente a la ridícula necesidad de fundamentar nuestro nacionalismo intelectual, hinchado de valores falsos que al primer pinchazo se desinflan como chanchitos...Martín Fierro siente la necesidad imprescindible de definirse y de llamar a cuantos sean capaces de percibir que nos hallamos en presencia de una nueva sensibilidad y de una nueva comprensión, que, al ponernos de acuerdo con nosotros mismos, nos descubre panoramas insospechados y nuevos medios y formas de expresión (Manifiesto, 1994, p. 16).

La posibilidad de ascenso social, en tanto elemento estructural de la sociedad argentina, tendrá su correlato en la conformación del incipiente campo intelectual de aquella época. Los pensadores e intelectuales surgidos de las capas medias urbanas de origen inmigratorio, alfabetizados y escolarizados en las escuelas y universidades del país, prontamente se enfrentaron a las clases altas tradicionales y al dominio que ejercían sobre el campo intelectual y, por ende, en la construcción de la nacionalidad.

Para Martín Fierro, entonces, la nacionalidad se encontrará vinculada a esta necesidad de renovación estética que impulsa desde sus páginas (Sarlo, 1997, p. 235). Esta renovación no será sin un manifiesto que defina las líneas centrales de acción del grupo. En el mismo se encuentran algunas directrices del momento juvenil que se posiciona "frente a la funeraria solemnidad del historiador y del catedrático, que momifica todo cuanto toca". Otro elemento a tener en cuenta, y que se desarrolla directamente con este trabajo, consiste en el tratamiento que le dará la publicación a los temas y personajes vinculados con la realidad latinoamericana. Frente a ello:

Martín Fierro cree en la importancia del aporte intelectual de América, previo tijeretazo a todo cordón umbilical. Acentuar y generalizar, a las demás manifestaciones intelectuales, el movimiento de independencia iniciado por

\section{(1)(1) $(9$}


el idioma, por Rubén Darío, no significa empero, que habremos de renunciar, ni mucho menos, finjamos desconocer que todas las mañanas nos servimos de un dentífrico sueco, de unas toallas [sic] de Francia, o de un jabón inglés (Manifiesto, 1994, p. 16).

Con el "tijeretazo" se refiere a la relación de dependencia a Europa, para lo cual Martín Fierro acuerda con la perspectiva de Pedro Henríquez Ureña en cuanto al reconocimiento de la herencia europea y la necesidad de independizarse de la misma, a la que la publicación tratará de contribuir.

Otro elemento interesante es la conformación de la editorial Martín Fierro-Proa, a la par de la revista. Proyecto nacido a sólo tres meses de la aparición del periódico, cuyos fundadores son Evar Méndez, Ricardo Güiraldes y Oliverio Girondo. Organismo autónomo, independiente del periódico, nace como una lógica prolongación de la vida literaria impulsada por la publicación. ${ }^{9}$ Como elemento a destacar, se estableció el pago de derechos de autor, jerarquizando la labor literaria del hombre de letras dentro del quehacer cultural nacional.

Con el arribo del flamante embajador mexicano a Buenos Aires, la publicación también ofreció el 17 de septiembre un banquete de bienvenida a modo de agasajo. En el mismo, participan varias publicaciones amigas de los martinfierristas, como Inicial, Valoraciones y la Revista de América. En la reunión "se encontró la intelectualidad, la literatura y el arte nuevos de Buenos Aires y La Plata" ${ }^{10}$

Nuevamente, se manifiesta la fraternidad del grupo martinfierrista con la transformación en el México posrevolucionario (de la mano de Álvaro Obregón y José Vasconcelos), del cual Alfonso Reyes se convierte en embajador de la cultura. En su discurso, Pablo Rojas Paz afirma que: "Ha venido Usted a un país en donde toda inquietud tiene su asiento y desde acá advertimos con mirada fraternal la intensa transformación que Méjico [sic] está soportando para hacerlo digno de realizar una parte del porvenir del mundo.

9 Editoriales Proa y Martín Fierro. Martín Fierro, año III, núm. 34, 6 de octubre de 1926, s/p. En Martín Fierro (1994). Dicha editorial publicará los Cuadernos del Plata, iniciativa de Alfonso Reyes en Argentina.

${ }^{10}$ Pablo Rojas Paz. Homenaje a Alfonso Reyes. Martín Fierro, año IV, núms. 44-45, agosto-noviembre de 1927. En Martín Fierro (1994, s/p.).

\section{()(1) $(9$}


Martín Fierro, junto a su pampa de horizontes tardíos, se quita el sombrero y lo saluda." ${ }^{11}$

Sin duda, Reyes es recibido como embajador cultural de aquel universo de cambios que constituyó el México posrevolucionario. La intelectualidad de Martín Fierro logra ver en el mexicano una continuidad del proceso democratizador que había dado forma a la Argentina de los años veinte y el camino hacia donde había que dirigirse.

En el caso de Henríquez Ureña, pudo verse una escasa participación en las páginas de la publicación, más allá de la supuesta consideración del dominicano como maestro y mentor de los jóvenes martinfierristas. ¿A qué pudo deberse esto? En términos generales, la publicación continúa en la línea de sostenerse como baluarte de la nacionalidad. Para ello, tomará algunas referencias que le permitan reforzar esta idea de identidad a partir de un nacionalismo literario, construido a partir del rescate de invenciones culturales como el campo y el gaucho, sujeto social ya desaparecido por aquellos años, sustituido por el peón de estancia.

En cuanto a los artículos publicados, solamente aparece un artículo de Pedro Henríquez Ureña (1925), considerado uno de los referentes americanos del grupo, ${ }^{12}$ mientras que el foco de atención está en la figura de Alfonso Reyes, que publica en Martín Fierro una sección dedicada a todos los nuevos poetas mexicanos que, posteriormente, serán conocidos como Los Contemporáneos. ${ }^{13}$ Bajo el nombre "Seis poetas nuevos de México", Salvador Novo, Bernardo Ortiz de Montellano, Carlos Pellicer y Xavier Villaurrutia, además de las exposiciones de Manuel Rodríguez Lozano y Julio Castellanos, acompañados por el dibujante Adolfo Best, fueron los artistas y poetas mexicanos que aparecieron en este apartado de homenaje a México (Seis, 1927).

La publicación destina también un espacio para la promoción de Pero Galín, de Genaro Estrada, que gracias a las gestiones de Reyes se hace conocida entre los escritores locales. No cabe duda que durante esos años, Estra-

11 Pablo Rojas Paz. Homenaje a Alfonso Reyes. Martín Fierro, año IV, núms. 44-45, agosto-noviembre de 1927. En Martín Fierro (1994, s/p).

${ }^{12}$ Es Ricardo Molinari quien, en un artículo sobre Alfonso Reyes, relata uno de sus múltiples viajes a la casa de Pedro Henríquez Ureña a La Plata, en compañía de Jorge Luis Borges y otros jóvenes, para conocer las novedades del escritor regiomontano a la vez que el dominicano les recitaba sus versos. Véase Ricardo Molinari. Alfonso Reyes. En Martín Fierro (1994, p. 331).

${ }^{13}$ Verso y prosa de Alfonso Reyes y páginas dedicadas a México por estadía de Alfonso Reyes. Martín Fierro, año IV, núm. 42, 10 de junio de 1927. En Martín Fierro (1994).

\section{()(1) $(9$}


da desempeñó un papel significativo en el desarrollo de la cultura mexicana como escritor, editor, erudito y promotor de diversas empresas. Tenía un amplio conocimiento de las letras patrias y extranjeras (especialmente de las francesas); por lo visto Estrada era la persona ideal para ayudar a Reyes en su afán de llegar a un mayor acercamiento y comprensión entre México y Argentina (Reyes y Estrada, 1993, p. 13). ${ }^{14}$

El surgimiento de la publicación mexicana Contemporáneos, para 1928, le demandó a Estrada la petición al embajador Reyes de colaboraciones argentinas para la revista, las cuales tardaron en llegar. Los Cuadernos del Plata alfonsinos fueron reseñados por Bernardo Ortiz de Montellano para 1929, mientras que la única colaboración argentina de renombre consistió en el poema "Recoleta" de Jorge Luis Borges. ${ }^{15}$ Resquemores, envidias y recelos separaron a los representantes de las vanguardias argentina y mexicana de un camino propuesto por Reyes, Estrada y Henríquez Ureña:

En el mundo de la nueva literatura hay una actitud defensiva contra México. A la vez que en lo político, aplauden a México, a la vez que se dan cuenta de que en nuestro país hay un gran movimiento de opinión general hacia la Argentina, tienen muchos cargos contra la nueva literatura mexicana. Están muy resentidos. [...] están muy celosos, pero justo es decir que a solas, reconocen la superioridad. [...] cargos concretos: la conferencia de Torres Bodet sobre la literatura argentina no se la perdonan todavía. Cuando la disputa sobre el meridiano literario, Ulises dijo cosas contra la Argentina. ${ }^{16}$

Finalmente, Reyes admitió que no ha podido obtener contribuciones porteñas para Contemporáneos debido a cierta actitud inherente en los argen-

${ }^{14}$ Genaro Estrada era escritor y secretario de Relaciones Exteriores de México.

${ }^{15}$ Jorge Luis Borges. Recoleta. Contemporáneos, núms. 40-41, septiembre-octubre de 1931, p. 135. En Durán (1973).

${ }_{16}$ Carta de Alfonso Reyes a Genaro Estrada, 21 de enero de 1929. En Reyes y Estrada (1993, pp. 184-185). Particularmente, Reyes se refiere a la polémica surgida frente a la publicación de La Gaceta de Madrid, considerar a esta como el meridiano continental de las letras y de las artes. A esto, los miembros de Martín Fierro responden planteando el mencionado "tijeretazo" o rompimiento de lazos con la tradición española, en busca del derecho de crear una tradición propia, americana. Lo que ocurre con Contemporáneos es una clara reivindicación de un hermanamiento con el hispanismo promulgado por La Gaceta, en desmedro de la postura argentina de considerar como meridiano de las letras y las artes no ya a Madrid, sino a Buenos Aires. Para más datos, véase García Gutiérrez (1996).

\section{()(1) $(9$}


tinos para quienes, según don Alfonso, "no existe más que la Argentina o lo que halaga a la Argentina, es decir, Europa” (García Gutiérrez, 1996, p. 16).

\section{ALFONSO REYES, EMBAJADOR DE LAS LETRAS MEXICANAS}

Para julio de 1927 Alfonso Reyes, designado embajador de México en Argentina, llega al Río de la Plata y es recibido por la intelectualidad local. La prensa argentina no dejará de cubrir el acontecimiento, ya que revelaba dos aristas: por un lado, una de índole institucional manifestada en la consumación, luego de varios años de espera por parte del gobierno mexicano, de ascender las representaciones diplomáticas argentina y mexicana al rango de embajadas; por otro -el que más nos interesa en este trabajo-, es el tibio recibimiento de Reyes, debido al conocimiento dentro de los círculos argentinos de la preferencia del mexicano por su vida en París, la cual debe abandonar por motivos relacionados con la gestión diplomática.

Los responsables de la revista Nosotros ofrecieron un banquete de bienvenida al representante mexicano, reseñado en el artículo "Nosotros': Nuestra demostración a Alfonso Reyes". En esa ocasión tomaron la palabra Ricardo Rojas, rector de la Universidad de Buenos Aires; por Nosotros, Emilio Suárez Calimano; por Valoraciones, el joven estudiante Aníbal Sánchez Reulet; $y$ el poeta Baldomero Fernández Moreno recitó una salutación a Alfonso Reyes. Asistieron, entre otros, Alfredo Bianchi y Roberto Giusti, directores de Nosotros. Pedro Henríquez Ureña, Alfonsina Storni, el pintor Emilio Petorutti y Jorge Luis Borges.

Ricardo Rojas da la bienvenida por parte de los escritores argentinos al representante de la embajada y, a la vez, voz espiritual de su país:

Hasta hace pocos años, México era para nosotros una comarca de leyenda, [...] más he aquí que a toda esa visión de leyenda se ha sucedido otra más actual y más humana, pues hoy sabemos que México es la avanzada de nuestra América Latina, y un campo de experimentos que interesan a todas las naciones de nuestra raza. Esto es lo que en los últimos años vinieron a hacernos comprender los escritores que México envió a sus legaciones del Plata, y lo que Alfonso Reyes continuará enseñándonos con eficacia magistral (Nuestra, 1927, p. 109).

\section{()(1) $(9$}


De esta manera, Reyes fue simbólicamente incorporado a la "república de las letras" argentina, bajo el beneplácito de los exponentes más importantes del panorama intelectual rioplatense del momento. Sin embargo, Rojas reconoce el escaso conocimiento que tenían los argentinos sobre la realidad del México contemporáneo. La experiencia traumática de la revolución había sido recibida desde la prensa y, gracias a la delegación estudiantil que visitó México por 1921, pudo tener más certezas sobre la nueva apertura posrevolucionaria. Rojas convoca a los presentes y, por medio de ellos, a ambos pueblos, a entenderse a pesar de las distancias, puesto que hablamos la misma lengua y compartimos los mismos ideales, cifrados aquí por el sol de nuestro escudo y allá por el ave caudal que estrangula a una serpiente (Nuestra, 1927, p. 110).

Sugerente y polémico por demás, resultó el ensayo de Alfonso Reyes publicado por Nosotros, el cual se denominó "Palabras sobre la nación argentina”. Este fue resultado de una radiocomunicación por Radio Buenos Aires realizada bajo los auspicios del círculo universitario Intemerandus el 29 de agosto de 1929 (véase Reyes, 2010, p. 150). Algunos elementos sobresalientes en el análisis constituyen su condición de extranjería, la inmigración y lo que devino en llamar las "apariencias porteñas", o los modos de ser del habitante de Buenos Aires.

Reyes se posiciona con una mirada exógena al fenómeno argentino, mirada que, según su parecer, le permite establecer algunas impresiones valiosas sobre su entorno: "He pensado que las impresiones de un extranjero (que no lo es tanto) sobre ciertos rasgos fundamentales de la nación argentina podrían ofrecer cuando menos, alguna curiosidad" (Reyes, 1930, p. 306). En este sentido, para Reyes (2010), una de las deudas que debe saldar el pueblo argentino es la de su naturaleza, constituida por un alto contenido inmigrante: "Creo honradamente, que todavía a orillas del Plata tiene que liquidarse la cuenta histórica que ya conocemos por el ejemplo de la Roma clásica: el duelo entre los patricios y el pueblo de procedencia extranjera, que acaso acabe por dar otro carácter inesperado a las nacionalidades del sur" (Reyes, 1930, p. 308). Este elemento, considerado fundamental para Reyes, le permite afirmar entre otras cosas, que: "La Argentina es una nación de creación voluntaria. La hizo la conciencia de los hombres, de los individuos. Es casi, el fruto de un deseo. El colono encontró aquí tribus nómadas sin yacimientos de civilización y tuvo que importarlo todo consigo -jhasta los parásitos!" (Reyes, 1930, p. 311).

Una nación generada por propia voluntad, que debe hacerse desde los cimientos para construir un "nosotros" nacional, una patria:

\section{()(1) $(9$}


Esta inmensa voluntad colectiva, que flota sobre el país como una divinidad tutelar, se apodera sin remisión del hijo de extranjeros. Y niños de todos los apellidos y llegados de todos los puntos de la tierra entonan en las escuelas públicas el mismo himno y se sienten, igualmente deudores a los mismos padres de la patria. Esto argentinos, es una patria y no una casualidad geográfica. Esto argentinos, es una nación fundada en una idea, libremente escogida por un genio de libertad, sabiamente inspirada por un estímulo de disciplina, sin compromisos con el azar y apenas con un leve peso del pasado. Con el retruécano gramatical conocido, diremos que esta Patria es filia: hija de todos los ciudadanos, que día por día la están queriendo y engendrándola según la desean (Reyes, 1930, p. 306, cursivas mías).

La mirada de un extranjero reconocido por el ambiente cultural argentino es por demás crítica. Para 1930, Reyes incluirá un Apéndice ${ }^{17}$ al texto, en el que señala los malos entendidos sobre las clases privilegiadas y las masas inmigrantes llegadas al país. Las primeras proyectan el modo de ser argentino, que los extranjeros según Reyes (1996) intentan reproducir:

Y en la Argentina, [las clases privilegiadas] producen una verdadera fascinación sobre la periferia, a través precisamente de ese conjunto de ideales, hábitos, maneras de ser y de obrar, trajes y ademanes que se llaman la mundanidad. Hasta el trabajo intelectual y artístico, una vez aceptado como uno de los caminos de acceso a la mundanidad, se ha visto, por eso, desarrollado en términos de verdadera superproducción, de oferta mayor que la demanda, como lo saben bien todos los editores, libreros y críticos argentinos (p. 38).

Resulta interesante ver cómo Reyes reflexiona también sobre los mecanismos de consagración de la nueva intelectualidad en el Río de la Plata, como un camino de acceso a la mundanidad, o dicho de otro modo, de pertenencia a las clases altas del país.

En busca del Reyes íntimo, el que escribe en su diario, este ve a la sociedad argentina como una serie de sectores sociales sin relación entre sí. En cartas confidenciales a Genaro Estrada, Alfonso Reyes realiza una somera descripción de la sociedad local de aquel entonces caracterizándola entre los de abajo, los de en medio y la aristocracia, pero sobre todo, utilizando en

17 Tomamos el mismo de Reyes (1996, pp. 36-41).

\section{()(1) $(9$}


clave algunos elementos que permiten desentrañar la real Buenos Aires conocida por el mexicano:

"Los de abajo", los compadritos amargos que muelen tangos en los organillos a la luz del farol apache, probablemente son muy pintorescos e interesantes, pero confieso que aún no bajo hasta esos fondos húmedos de la ciudad, a pesar de mi amistad con los "martinfierristas" [...] "Los de en medio": Gente triste, producto de la inmigración. Todo inmigrante es un náufrago. [...] Todo inmigrante, además de náufrago, es un Eneas que se ha dejado a la espalda una ruina, una ciudad quemada, una familia perdida, una historia de presidio o de fracaso [...] La aristocracia se forma de hijos y descendientes de los hombres que hace sesenta, o a lo sumo cien años, se enriquecieron en las estancias, o tomaron parte en la vida pública. ${ }^{18}$

El mundo de la prostitución y los bajos fondos son retratados por Reyes como los "de abajo", los cuales todavía no se aventuraba a conocer hasta el momento. Reyes pretende describir una realidad local cada vez más lejana y paulatinamente agresiva, y de la cual decide poner distancia, la cual manifiesta en su Diario, con fecha de 8 de enero de 1930:

Peores cada vez mis impresiones del ambiente literario argentino, donde a nadie le importa la literatura, sino la politiquilla literaria de los grupos o patotas, y donde los individuos de los grupos se traicionan entre sí constantemente. A la realidad sustituye un fantasma de murmuraciones. Muy raro todo. Quédense solos y arréglense solos. Yo para mi coleto, he decidido alejarme prácticamente y vivir con la mente en otra parte. Y no es queja contra "personas": sería ingrato. ${ }^{19}$

Esta confesión reveladora permite anudar algunas de las problemáticas propias del campo literario argentino para aquel momento. Las tensiones y discusiones propuestas por la vanguardia representada en Martín Fierro, enfrentadas a personajes controvertidos como Leopoldo Lugones, sumada a la languidez de Nosotros y el debate sobre la nacionalidad en la literatura,

${ }^{18}$ Carta confidencial de Alfonso Reyes a Genaro Estrada, 15 de diciembre de 1927. En Reyes y Estrada (1993, pp. 76-77).

19 París, 19 de marzo de 1927, en Reyes (2010, p. 164).

\section{()(1) $(9$}


posicionan a Reyes en un terreno marginal. El sorpresivo suicidio de Lugones en 1938 fue material para un homenaje que realizó Reyes para Nosotros: ${ }^{20}$

Nacido en el modernismo americano [...] en los últimos años lo encontramos en plena evolución, en vida constante, inclinado amorosamente sobre los asuntos populares y escribiendo sencillos poemas del tipo de nuestros corridos mexicanos, poemas impregnados de un intenso aroma folklórico que saben a yerba sanjuanera y a recién ordeñada leche. [...] Hombre de la provincia, trae desde su terruño cierto empuje de conquistador de capitales, reacio y díscolo por veces. E impregnado de historia patria, su conversación era un archivo abierto para recorrer los pasos de la vida argentina (Reyes, 1938, pp. 344-345).

Reyes, deleitado por la personalidad del argentino, quien modificó radicalmente su postura ideológica para aquellos años, escribe en su homenaje una estampa literaria, que retrata de cuerpo entero la figura del escritor sureño:

De cuerpo regular, más bien alto. Sólo bigote. Espejuelos. Acento argentino. Contento, orgulloso de su patria como problema étnico, en él he aprendido el orgullo de no tener problemas de raza. Todo mexicano suficientemente desinteresado sacará provecho de hablar con un argentino; es la perspectiva opuesta. No es político, pero interviene en todo. Es pedagogo. Es hombre de todos los instantes, tiene cien mil aspectos, todos robustos y grandes. Me parece que todo americano tiene la obligación de imitar su energía y fecundidad. A Europa no le podemos hacer ningún bien; pero a nuestras pobres tierras americanas, sí. Y para eso, hay que saber, como él, ser poeta y pedagogo, historiador y periodista, erudito e imaginativo. ${ }^{21}$

${ }^{20}$ Escritor argentino con el que Reyes ya había tenido contacto durante su estadía en Europa en 1914. El suicidio de este último, considerado árbitro de las letras argentinas de aquel entonces, provoca la adhesión al masivo pésame de las letras argentinas.

${ }^{21}$ El escritor argentino Leopoldo Lugones era perfectamente conocido por Henríquez Ureña y Reyes inclusive antes de que llegaran a Argentina y tomaran contacto con la intelectualidad local. En el caso de Reyes, este había conocido a Lugones durante su estadía en el país galo producto del exilio forzado en 1913, país al que se dirige con un empleo en la legación mexicana. Era la segunda vez que Lugones visitaba Francia, pero esta vez tenía en sus manos el proyecto de publicar una revista sobre temas americanos en francés, la Revue Sudaméricai-

\section{()(1) $(9$}


Henríquez Ureña lo considera como una de las influencias de la generación del Ateneo de la Juventud y le ofrece unos años antes, para 1914, por medio de Reyes, ya que ambos se encontraban en París, realizar las diligencias necesarias para dar a conocer su obra en México, en la librería de Gamoneda (Reyes y Henríquez, 1986, p. 254). Por último, en el marco de su trabajo sobre Rubén Darío, en su obra Horas de Estudio, el dominicano lanza la siguiente sentencia: "Si a alguien pudiera darse el título de Góngora Americano, a Leopoldo Lugones le correspondería en todo caso: él es quien ha popularizado entre nosotros un estilo imaginativo singular, cuyo más notable recurso es la transmutación de lo objetivo en subjetivo y viceversa (Henríquez, 2001, p. 78).

Años más tarde de formulada dicha sentencia, Reyes le confesará por carta a Henríquez Ureña haberle transmitido a Lugones esta frase, durante uno de los múltiples encuentros en París, frente a la cual este último dijo sentirse muy honrado. ${ }^{22}$

Desde muchos años antes de la llegada de Henríquez Ureña y Reyes (1908), el espacio de Nosotros constituyó para Pedro Henríquez Ureña y para su discípulo, Alfonso Reyes, la apertura literaria hacia Argentina. Para dicho momento, las ideas fundamentales referían a la construcción de una nación en términos literarios para el Río de la Plata. Para la década del veinte, y luego de varios torbellinos democratizadores, como la apertura democrática radical y la reforma universitaria; Nosotros comenzó a tambalear dentro del espacio literario. El campo literario, hegemonizado por esta publicación, entró en crisis para reacomodarse en una nueva generación con una clara mirada hacia el "ser nacional": la vanguardia.

\section{CONCLUSIONES}

La llegada de Pedro Henríquez Ureña a Argentina en 1924 y posteriormente la de Alfonso Reyes en 1927, inauguraron un espacio de nuevas relaciones entre intelectuales y exponentes de la cultura mexicanos en Argentina. De

ne. Dicha publicación se verá interrumpida por el comienzo de la primera guerra mundial, siendo su último número el de julio de 1914 (Reyes y Henríquez, 1986, p. 232).

${ }^{22}$ Carta de Alfonso Reyes a Pedro Henríquez Ureña, 14 de julio de 1914. En Reyes y Henríquez (1986, p. 400).

\section{()(1) $(9$}


una forma más precisa, y al recordar que Henríquez Ureña era dominicano de nacimiento (ascendencia presente a lo largo de su obra), la presencia de los ideales del Ateneo de la Juventud en Buenos Aires, sumada a los insuflos posteriores a la Reforma Universitaria de 1918, generaron una extensa red de pensadores que, gracias a las publicaciones literarias y periódicas, fue expandiéndose a lo largo del continente. A lo largo de estas páginas, analizamos su presencia en el medio intelectual rioplatense, tomando como punto de partida la revista Nosotros, espacio legitimador de las corrientes literarias del momento, gracias a la presencia de la pluma de Leopoldo Lugones, por ejemplo.

Por su parte, la emergencia de la juventud como sujeto político, llevó al surgimiento de muchas publicaciones destinadas a dicha tribuna. Valoraciones fue uno de los casos, y en su plataforma tuvieron gran protagonismo las filias generadas en el Congreso Internacional de Estudiantes de 1921. Artículos de Pedro Henríquez Ureña así como de Daniel Cosío Villegas, novedades editoriales de Alfonso Reyes y José Vasconcelos demostraban una profunda cercanía entre el estudiantado latinoamericano en pos de la conformación de una nueva conciencia continental gracias al magisterio de José Ingenieros, Alfredo Palacios y el propio Henríquez Ureña.

Por último, la emergencia de la vanguardia literaria en el Río de la Plata estuvo íntimamente relacionada con la emergencia de publicaciones como Proa e Inicial, pero fue la tercera Martín Fierro la que logró aglutinar los temas y a los protagonistas, destacándose la presencia de Jorge Luis Borges, Evar Méndez, Francisco Luis Bernárdez, Xul Solar, Emilio Pettorutti entre muchos otros. En este espacio, y dentro de los postulados vanguardistas de la época, fue Alfonso Reyes quien acompañó de forma más próxima, impulsando la promoción de la vanguardia mexicana, a Los Contemporáneos, dentro de las páginas de la revista. Se generó así un ríspido e intenso debate entre grupos vanguardistas cuyas consecuencias tuvieron estricta relación con temas nacionalistas, en los albores de los años treinta del siglo xx.

En otras palabras, la presencia de México en la Argentina de los años veinte y comienzos de los treinta fue vital a la hora de pensar en los puentes elaborados por los intelectuales que generaron empresas posteriores de una envergadura tal como los exilios de los setenta, en el marco del crecimiento del autoritarismo y el terrorismo de Estado en el Cono Sur de América Latina. Enarbolar el espíritu de la Reforma, sumado a los planteos del Ateneo de la Juventud que se materializaron en las publicaciones literarias rioplatenses de los años veinte es pensar en alternativas de común unión entre pensadores

\section{()(1) $(9$}


en América Latina, superando las cómodas categorías nacionales y en pos de la gestación de redes y espacios de creación comunes a todo el continente.

\section{LISTA DE REFERENCIAS}

Beigel, F. (2003). Las revistas culturales como documentos de la historia latinoamericana. Utopía y Praxis Latinoamericana, 8(20), 100-105. Recuperado de http://produccioncientificaluz.org/index.php/utopia/issue/view/314

Bustelo, N. (2015). La Reforma Universitaria desde sus grupos y revistas: una reconstrucción de los proyectos y disputas del movimiento estudiantil porteño de las primeras décadas del siglo xx (1914-1928) (Tesis doctoral). Universidad Nacional de la Plata, La Plata, Argentina.

Crespo, R. (2010). Revistas en América Latina, proyectos literarios, políticos y culturales. México: Centro de Investigaciones sobre América Latina y el Caribe-unAm.

Delgado, V. (2009). El nacimiento de la literatura argentina en las revistas literarias (18801915). Rosario: Beatriz Viterbo.

Díaz Quiñones, A. (2006). Sobre los principios. Los intelectuales caribeños y la tradición. Bernal: Universidad Nacional de Quilmes.

Durán, M. (1973). Antología de las revistas contemporáneas. México: Fondo de Cultura Económica.

García Gutiérrez, R. (1996). Ulises vs. Martín Fierro (notas sobre el hispanismo literario de Contemporáneos. Literatura Mexicana, 7(2), 407-444. Recuperado de https://revistas-filologicas.unam.mx/literatura-mexicana/index.php/lm/article/ view/242/242.

Henríquez Ureña, P. (enero de 1924). Poeta y luchador. Valoraciones, I(2).

Henríquez Ureña, P. (abril de 1925). Héctor Ripa Alberdi. Nosotros, XIX(191).

Henríquez Ureña, P. (5 de agosto de 1925). En la orilla. Martín Fierro, II(20).

Henríquez Ureña, P. (mayo de 1928). Enrique Dreysin. Valoraciones, 5(12).

Henríquez Ureña, P. (1929). Seis ensayos en busca de nuestra expresión. En Obra crítica. E. S. Speratti Piñero (ed.). México: Fondo de Cultura Económica.

Henríquez Ureña, P. (1969). La Universidad. En Universidad y Educación. México: UNAM.

Henríquez Ureña, P. (2001). Obra crítica. E. S. Speratti Piñero (ed.). México: Fondo de Cultura Económica.

Henríquez Ureña, P. y Reyes A. (1986). Epistolario intimo (t. III). Santo Domingo: Universidad Pedro Henríquez Ureña. 
Intenciones (septiembre de 1923). Valoraciones, 1(1). La Plata, Argentina.

Lafleur, H., Provenzano, S. y Alonso, F. (1968). Las revistas literarias argentinas (18931967). Buenos Aires: CEAL.

Manifiesto (1994). Martín Fierro.

Martín Fierro (1994). [facsimilar]. H. Salas (ed.). Buenos Aires: Fondo Nacional de las Artes.

Masiello, F. (1986). Lenguaje e ideología: Las escuelas argentinas de vanguardia. Buenos Aires: Hachette.

Melgar Bao, R. (2010). Las universidades populares en América Latina (19101925). Revista Pacarina del Sur. Recuperado de http://www.pacarinadelsur.com/ home/amautas-y-horizontes/149-las-universidades-populares-en-america-latina-1910-1925.

Myers, J. (2005). Gênese "ateneísta" da história cultural latino-americana. Tempo Social, revista de sociología da USP, 17(1). DOI: http://dx.doi.org/10.1590/ S0103-20702005000100002

Nuestra demostración a Alfonso Reyes (octubre de 1927). Nosotros, xxi(221).

Pita González, A. (2009), La Unión Latinoamericana y el boletín Renovación. Redes intelectuales y revistas culturales en la década de 1920. México: El Colegio de México/ Universidad de Colima.

Quattrocchi-Woisson, D. (1997). Las revistas en la vida intelectual y política. En Nueva historia de la nación argentina (t. x, pp. 165-199). Buenos Aires: Planeta.

Reyes, A. (enero de 1924). Del libro inédito, Calendario. Valoraciones, I(2).

Reyes, A. (marzo de 1930). Palabras sobre la nación argentina. Nosotros, XXIV(250).

Reyes, A. (mayo-julio de 1938). Homenaje a Leopoldo Lugones. Nosotros, 2a época, II (26-28).

Reyes A. (1996). Obras completas (t. IX Norte y Sur). México: FCE.

Reyes A. (2010). Diario II (1927-1930). Ed. y notas, A. Castañón. México: FCE.

Reyes A. y Estrada, G. (1993). Con leal franqueza (t. II). México: El Colegio Nacional.

Reyes, A. y Henríquez Ureña, P. (1986). Correspondencia (1907-1914). México: FCE.

Reyes, A. y Ocampo, V. (1983). Cartas echadas (1927-1959). México: Universidad Autónoma Metropolitana.

Romano, E. (2004). Revolución en la lectura. El discurso periodístico literario de las primeras revistas ilustradas rioplatenses. Buenos Aires: Catálogos.

Salas, H. (1994). Un salto a la modernidad. En Martín Fierro [edición facsimilar]. H. Salas (ed.). Buenos Aires: Fondo Nacional de las Artes.

Sancholuz, C. (2013). Desplazamiento y nuevos arraigos: Pedro Henríquez Ureña y la revista platense Valoraciones. Anales de Literatura Hispanoamericana, 42, 91-105.

\section{(1) (1) $(9$}


Sarlo, B. (1988). Una modernidad periférica: Buenos Aires 1920 y 1930. Buenos Aires: Nueva Visión.

Sarlo, B. (1997). Vanguardia y criollismo. La aventura del Martín Fierro. En C. Altamirano y B. Sarlo, Ensayos argentinos. De Sarmiento a la Vanguardia. Buenos Aires: Ariel.

Seis poetas nuevos de México (junio-julio de 1927). Martín Fierro, IV(42).

Tarcus, H. (2001). Mariátegui en Argentina, o las políticas culturales de Samuel Glusberg. Buenos Aires: Biblioteca Flacso/El Cielo por Asalto.

Weinberg, L. (2013). Ensayo y sociabilidad (texto inédito). México: Centro de Investigaciones para América Latina y Caribe.

Yankelevich, P. (1997). Miradas australes. Propaganda, cabildeo y proyección de la revolución mexicana en el Río de la Plata (1910-1930). México: Instituto Nacional de Estudios Históricos de la Revolución Mexicana.

\section{OTRAS FUENTES}

Bergel, M. (2006). Un caso de orientalismo invertido. La Revista Oriente (1925-1926) y los modelos de relevo de la civilización occidental. Prismas, 10, 99-117. Recuperado de http://www.unq.edu.ar/advf/documentos/56741e85555c4.pdf

Schwartz, Jorge (2002). Las vanguardias latinoamericanas. Textos programáticos y críticos. México: Fondo de Cultura Económica. 